\title{
Study on the Construction Techniques of Virtual Environment in Traditional Chinese Landscape Painting
}

\author{
Bing Hao \\ Henan University Minsheng College \\ Kaifeng, China 475000
}

\begin{abstract}
The construction of virtual environment is an important technique in Chinese traditional landscape painting. It is a profound embodiment of traditional Chinese literati's philosophy of nature. It developed from analogy of the landscape painting to doctrine in the Wei and Jin Dynasties, the virtual environment of landscape painting close to nature in the Tang Dynasty, to the realistic environment of painting in the Two Song Dynasties, which all reflect the mature and development of mainstream humanistic thought and creation techniques of landscape painting in each period. The thesis mainly analyzes the creating techniques of virtual environment in traditional Chinese landscape painting, and expounds the creation of the virtual environment of the realistic-environment landscape painting in the Five Dynasties and the Two Song Dynasties.
\end{abstract}

Keywords - traditional Chinese painting; landscape painting; construction of virtual environment

\section{INTRODUCTION}

The construction of the virtual environment is a commonly used technique in Chinese landscape painting. It is an expressive form of the natural representation of the heavens and the earth under the influence of metaphysics and Taosim of the ancient Chinese ancestors. In the Wei and Jin Dynasties, the dynasty changed frequently as a result of the war. The metaphysics is popular. The celebrities began to love in the landscape, pursuing the natural integration with the Taoism. It plays an important role in promoting the development of landscape literature. Since Jin Dynasty, traditional Chinese painting has been influenced by the landscape culture under metaphysics. Landscape painting began to appear in the bud. The development of landscape painting is based on the humanistic spirit and mainstream values of the time. It is a reflection of Chinese humanistic philosophy. The creation of false alarms in landscape paintings also reflects the humanistic value of the era. It is of great significance to reflect the cultural value of contemporary landscape painting creation.

\section{THE EARLY EXPRESSION AND CONSTRUCTION OF VIRTUAL ENVIRONMENT}

The early landscape painting is a concrete image of landscape literature. In the painting, the landscape painting appears mostly as the background. In order to set off the sagelike type of character, this is the initial expression of the landscape painting in the Wei and Jin Dynasties. At this time, the beauty of the virtual environment in landscape painting has not been fully revealed. Luoshen Fu Painting is one of the representative works of Dunhuang cultural paintings. In this picture, the landscape is still centered on the characters and the plot is the way of expression. In the picture, the spatial structure is described on the basis of pattern sketch, and the construction of virtual environment is not reflected. The expression of space and spirit is still a way of expressing the pattern. However, this style of painting lays a foundation for the development of the techniques of virtual-environment construction in the future landscape painting. From the study of Chinese traditional Chinese painting, it was found that in the period of the Liu Song of the Southern Dynasty, with the continuous development of the aesthetic thought, Wang Wei had developed a new technique for the creative techniques of landscape painting, which became an independent landscape painting method.

\section{A. Related Techniques and Comparative Study of Early Scenery Matching}

This thesis takes Gu Kaizhi's Painting Yuntai Mountain as the object of study. First, in the background composition, the whole picture is taken with three sections of the composition method from right to left. From the slight mask of the part of the picture to the hide and reveal of the scene, it used the appropriate composition technique. For example, it used scenery isolation and scenery shield to express space relationship, used springs, streams and ravine to clear space levels. At same time, it also used the hide and reveal method to sketch the dark or light relationship, as "one man hid behind a rock on the west with his clothing corner left outside, it is known a man behind the rock. The spatial relationship is quite delicate". At same time, it also used the distance of mountain to express the special distance. Secondly, in the modeling of the picture, the Yin and Yang expression technique is used to express volume. For instance, used the mutual superposition method to describe the volume of mountain rock, meanwhile, it also plays the role of space extension. For the pursuit of "posture", use the modeling method to outline and the dynamic and static relationship to set off by contrast. It not only makes it reveal but also gives people endless imagination. Thirdly, in color setting, express changes by arranging color of scenery and highlight space with dark and light background in addition 
to the shaping of overall reality, so that it is clearer in the sense of depth. For example, highlight the changes of space by the changes of dark and light colors. "A mountain has both light and shadow sides, auspicious clouds could be arranged floating from the east [1]." In addition, the fusion of colors can be used to show the space in the distance. At the same time, a fuzzy method is used to reduce the brightness of the whole color to express the empty and far distance of the distant scene. Through the main description of the background of the early mountains and rivers, it is found that the painting is expressed only from the composition, modeling and color setting. The techniques for creating the virtual landscape are not systematically expounded, which also shows some characteristics of the related techniques for the early landscape and scene matching.

\section{B. Related Techniques in the Early Independent Landscape Painting}

The appearance of the landscape painting school is produced by the formal cognition of the aesthetic system of landscape painting. Zong Bing and Wang Wei can be said to be the ancestors of the landscape painting school. They have made a preliminary study of their theory and related techniques. They have completely divided the landscape painting with the function of the original landmark guidance, and became a kind of pure landscape painting school. When it came to Xiao Ben of Southern Liang Dynasty, his artistic conception presented the form of remote space. It can be said that Xiao Ben was the first painter in the perspective sketch of the distant and near landscape. In the present knowledge of physics, reference substance is expressed in paintings.

As for the theoretical techniques of early landscape painting, the artistic conception of landscape painting has been developed into an independent school of painting in the period of the Southern Dynasty's Liu Song period. Zong Bing used the natural viewing of distant reflection to express the size in the picture. In technique, he used shape to paint shape and color to shape appearance, which is a creative technique showing a long distance in a small scroll in a nature way. Xiao Ze's Stream, Mountains and Pavilions have presented the beginning of concreting painting theory and law. In the use of techniques, it is more intensive in structure, color setting and inking than those of the early Southern Dynasties. It made a great progress from vague theory of landscape painting to systematic theory, which has made a theoretical underlay for Zhang Ziqian's Spring Outing Painting. From the techniques of Spring Outing Painting, it can be said that it is a direct embodiment of the landscape features of the Sui Dynasty. His creative techniques have made great progress, but there was still a lot of space for the development compared with the landscape painting in the Tang Dynasty. The expression of the techniques is still not in place. In overall color setting, he painted mountain rock with mineral blue, land and rock with green and foothill with mud golden. In arrangement of scenery, the overall scroll was divided into three parts, the lower left corner, the middle part and right part. The painter sketched chain of mountains with a small area at the lower left corner, and focused on the painting of water in the middle part with a larger layout. On the right part were mountains as the middle scenery. In distant description, it uses a descending-order painting technique. From the modeling, it is close to nature. The deficiency is that the distant sketch of scenery is not enough in expressive force, but it does not affect the overall spatial perception.

\section{THE CONSTRUCTION OF VIRTUAL ENVIRONMENT IN THE REALISTIC-ENVIRONMENT PAINTING IN THE FIVE DyNASTIES AND Two SONG DYNASTIES}

\section{A. Overview of the Techniques of "Realistic-environment" Landscape Painting}

From the analysis of its causes, "realistic-environment" landscape painting has been popular since the Two Song Dynasties. It is mainly because painters of Tang Dynasty had a new understanding of the aesthetic feeling of landscape painting. First, Father and son of $\mathrm{Li}$ family made a corresponding improvement on the creative techniques of the red and green landscape painting, and changed the form of landscape painting, breaking the past restriction of metaphysics form in the landscape painting. They began to use the form of ink and water to express the landscape painting. Secondly, in the inheritance of landscape painting, ink and water landscape painting was a new thing, so the predecessors had no systematic experience to learn from. There were only some creative techniques, so they put forward "there is no fixed skill in painting, likeness is skill; there is no fixed teacher for learning, truth is teacher." It means though we have no landscape painting techniques for inheritance, we can take nature as teacher and we can paint on the self understanding of water and mountain. In addition, poetry has developed rapidly in the Tang Dynasty. In the green and red landscape painting, painters preferred to quote poetry. They developed an ability of expressing the special distant artistic conception in the scroll from integrating this special artistic conception into the landscape scenery. As the saying goes "there is painting in a poem and poem in a painting". It can be said that the attainments of Chinese ink painting in the Tang Dynasty have laid a solid foundation for the two Song Dynasties, in techniques, understanding and related theories. In the two Song Dynasties, it was improved on the basis of drawing on the attainments of the landscape painting of the Tang Dynasty, forming the system theory of related experience, so that it reached the peak realm of realistic-environment landscape painting in the Song Dynasty.

The landscape paintings in the Two Song Dynasties focused on the management of position, and made great progress in the detail description and paid attention to realistic sketch. But here the realist sketch doesn't mean the description of objectively existing objects but real expression of object in ideal. It can be said the realistic environment was sketched by painter. It is real expression of painter's heart. So, painters of Five Dynasties and Two Song Dynasties also followed the natural law in the landscape painting, rather than reality in natural form. In the Two Song Dynasties, painters had made a great breakthrough in the overall system of landscape painting.

From the brush and ink vocabulary of the Northern School of Painting, the techniques of landscape painting in the Two Song Dynasties broke through the traditional tradition. Red 
and green landscape painting was changed into realistic landscape painting in Sui and Tang Dynasties. After the further evolution, it has been greatly developed along with the popular painting idea of taking advantages of hundreds of families at the time. However, the emperors in the Two Song Dynasties were fond of ancient things, so they also affected the painting style of landscape painting to some extent and made it partial to ancient style. The ink and wash vocabulary of realistic landscape painting was developed gradually from the Northern Song Dynasty. The wrinkle method appeared at that time laid the foundation for the brush and ink techniques of later landscape painting.

From the brush and ink vocabulary of the Southern School of Painting, it started from Dong Yuan's fiber-coating winkle method of the Five Dynasties and got a certain development and continuation in the early Song Dynasty. Dong Yuan had used this technique in his Xiaoxiang Painting. In painting mountain, use pots frequently and then connect them into area to express the luxuriant mountain range. In painting shoal, use the technique of plain sweeping to create a virtual distance realm. After that, many people imitated and developed the painting method. For example, Ju Ran wielded the brush with the long fiber-coating method to express the majesty of mountain and water.

From the founding to the middle of the Northern Song Dynasty, a considerable amount of painting techniques has been accumulated in the distance description of landscape painting. As Guo Xi put forward the form of "three distances", it has reached a new realm. The so-called "three distances" refer to: distances in height, horizon and depth. Distance in height refers that in relative low viewpoint, one looks up to the mountain, the peak stands in front, and clouds at the peak of mountain thin, so the view is clear, and in the effect of the picture shows a spectacular peak. Distance in horizon refers that when the view is parallel to the distant view, the scenery presents a fuzzy or clear state according to the actual situation of the cloud and fog, and the expression of the whole mood is relatively implicit. Distance in depth refers that in the case of higher view, you can see the rear and the front of the mountain, the sight distance is relatively far, and the dust fog has some interference to the sight, thus showing the fuzzy and blurred sense. Guo $\mathrm{Xi}$ has expressed distance of sceneries from different forms with his view of three distances. It enables the overall landscape painting presenting a three-dimensional realistic sense of space. It can be said it is ancient people's application of physics in landscape painting.

Analyze landscape painting from natural theory. The natural theory is a reflection of philosophy in the Song Dynasty. By studying the nature of things it expresses the sense of all things to the extreme. This philosophy is unavoidably presented in painting, such as the story of Zhao Jizhi's "peacock uplifting its left foot before flying" and junior Xin Jin's Noon Sun in Spring. They used this philosophy in the technique of landscape painting, which not only reflect the painting technique itself but also make a detailed description of the understanding of all things in the world. The philosophical thought of researching things had provided great help to the development of the ideology of landscape painting at that time. It enables various natural phenomena present in painting, summarizes related rules and forms systematic theory. In the form of geography, it points out the different forms of landscape in the north and the south, and also makes a detailed analysis and classification of the natural season, which provides a great help for the shaping of realistic environment.

\section{B. Analysis of the Construction Techniques of Virtual Environment in Realistic-environment Landscape Painting}

First of all, we should point out the characteristics of the virtual environment of realistic landscape painting, and it mainly manifested in three aspects. First, it is the lifelike realistic characteristic. In Two Song Dynasties, the expression of realistic environment of landscape painting had reached a new height and received the influence of the philosophical thought of researching the nature of things. It made the most practical outline of the objective existence of nature. At the same time, it makes the most visual and natural expression of virtual distance within eyesight. It is the real expression of virtual environment in realistic environment. In space shaping of virtual environment, it fully used the techniques of modeling, scenery setting and color setting. The expression of virtual environment is established on the distance, which is also in line with the theoretical basis of the landscape painting in the Southern Song Dynasty. The expression of space has made full use of the technique of distance. This kind of light, virtual, whole and simple feature extends the space of the picture to the infinite space of the painting or outside the painting, and thus completes the construction of virtual environment. Second: it is the poetic characteristic. In the Tang Dynasty, the poetry was developed in a blowout style. The scholars were proud of their ability to recite poetry. This thought had an inevitable influence on the field of painting. The first poetic expression was from Wang Changling. He first expressed it in his Poetics. In the Tang Dynasty, landscape painting combined with poetry, showing a form of "poetry in painting and painting in poetry". The so-called painting in poetry refers to that the brilliant words of poetry is associated with scenery and extended infinitely and become a manifestation of the virtual reality. The virtual and realistic combination forms unique environment. Third, it is the cyclic universal space characteristic. In landscape painting, distance expression really is not endless, but to show the universal space characteristic. It is a cyclic process of reciprocating space. In landscape painting the distance is expressed in a cyclic process of infinite, finiteness and infinite overall.

Secondly, it is pointed out that the method of handling virtual environment is based on Guo Xi's three distances. The three-distance space of Guo Xi put forward the corresponding creative technique for the distance features in the landscape painting. It is the painting feature of starting from different angles according to the different needs of distance. At the same time, put forward different proportion features according to the distance of scenery and enlarge or narrow it according to the actual proportion of reference objects to express the feature of distance and make the all sceneries at different distance in the whole scroll form a system. In addition, use nothingness to express the vision feature of distance. In addition, this expression feature is very common in real life. The sight will be vaguer and vaguer if the distance is far to the extreme, until 
the sight cannot reach. This expression is very common to express the distance in landscape painting.

\section{IN THE YUAN, MING AND QING DYNASTIES, THE \\ PAINTING TECHNIQUE CHANGES DOMINATED BY THE CONSTRUCTION OF VIRTUAL ENVIRONMENT}

\section{A. The Painting Technique Changes from the Yuan Dynasty to the Ming and Qing Dynasties}

In the Yuan Dynasty, the landscape painting showed several main characteristics. First, the development of paper making technology made paper certain popularity, so the painters of the Yuan Dynasty mostly used paper as material, and mostly used dry pen. Secondly, the wrinkle method of landscape painting in Yuan Dynasty originated from the Two Song Dynasties. But it developed again, and the brushwork was more loose and methodic. Second, the creation of the landscape was extended in the south, while the landscape painting of Yuan Dynasty began to combine poetry or inscription with landscape painting, making it with more artistic expression.

The main features of the landscape painting of Ming Dynasty are as follows: first, in the early Ming Dynasty, painter mainly referred to the painting techniques of the Two Song Dynasties, especially the Southern Song Dynasty. From the mid Ming Dynasty, the painting style of the Yuan Dynasty was gradually developed as the main reference. So, the painting style of Ming Dynasty is not stick to one pattern. Second, from the Ming Dynasty, with different painting methods, there were different landscape schools. They compared with each other, which directly promoted the perfection of related techniques of landscape painting system and different creative theories in Ming Dynasty. Generally speaking, the development of landscape painting in Ming Dynasty mostly inherited the painting techniques and styles of the preceding dynasties, and there was no special innovation.

In the Qing Dynasty, landscape painters preferred the ancient style. The corresponding painters were painters adhering to Ming Dynasty, such as, four monks of early Qing Dynasty, Xi Xian, Chen Zhuo, eight painters of Nanjing and Mei Qing. The two schools had a high achievement in landscape painting of Qing Dynasty. It also existed in other painting school. But in general it has no profound influence on the later generations. Especially, the adherent painters have played a certain role in the development of the landscape painting in the Qing Dynasty. Shi Tao is one of the representative painters among these adherent painters. His theory had made a great influence on the generation of modern landscape painting. On the whole, the adherent painters in the Qing Dynasty promoted the development of landscape painting and their achievements exceeded the Ming Dynasty.

\section{B. The Construction Techniques of Virtual Environment in Traditional Chinese Landscape Painting in the Yuan, Ming and Qing Dynasties}

Chinese traditional painting has been deeply influenced by Zen and Taoism since ancient times. Although Zen began to decline gradually from the end of Tang Dynasty, it has been widely spread in the folk. Especially, some scholars have been quite attainable in Zen Buddhism. It was started from Wang Wei. He introduced Zen into landscape painting, and then Su Shi, Liang Cuo, Fa Chang and others followed. But the spirit of Zen has not been embodied in reality because the only introduction of it. The actual embodiment of the virtual environment in the landscape painting originated in the Yuan Dynasty. First of all, it showed that the painters borrowed the landscape to express their thoughts, showing the characteristics of the freehand nature. The characteristics are reflected in that it is not restricted by real objective scenery in landscape painting to show the imagination of inner heart. There is a new requirement for people in the view of the painting. It may only be able to understand its profound meaning only with the author's artistic conception and thought, which is a spiritual level and a manifestation of abstract virtual environment. At the same time, in the language form of landscape painting, they also reflected the characteristics of the virtual distance. They focused on the expression of artistic conception of painting, creating a form of realistic and virtual painting. It was one of expression characteristics used by painters in the Yuan and Ming and Qing Dynasties. The overall summary is as follows: the construction of virtual environment in freehand landscape painting of Ming and Qing Dynasties shows the structure method of hiding reality into virtual landscape. At same time, they paid more attention to brushwork. In addition, the production and application of Chinese art paper made them have a new understanding on the usage of the materials. The introduction of poetry and prose inscription, the overall artistic level is obviously improved.

From the modeling structure, the three dynasties of the Yuan, Ming and Qing Dynasties showed two types in the construction of the virtual environment in the landscape painting: first, use the dense and sensitive method to form the structural zone with repeated wrinkle lines. Secondly, use wrinkle method to simplify structural line and shape. Virtual and real changes are obvious, and forms are varied. But the wrinkle line is relatively sparse. In the freehand process of brushwork and ink techniques, blended calligraphy into painting to show its refined characteristic from the Yuan Dynasty, which integrating calligraphy and painting into one and creating a new painting form. The representation of this virtual environment was reflected in the process of drawing and painting, and it has fundamental difference from painting style of the Tang and Song Dynasties. It is not being restricted by the existence of "reality", but embodying the leisurely and carefree mood integrating into the style of painting. In addition, the use of brushwork also embodied the existence of the virtual environment. From the Yuan Dynasty, the painting began to use the brushwork in the calligraphy, or thick or light, or broken or continued, showing the characteristics of emptily brushwork. This special brushwork system is an important reference for landscape painting of the Ming and Qing Dynasties. Painters of Ming Dynasty advocated this technique, and meanwhile they paid attention to the dense changes of ink and paper, making the whole landscape painting with illusory meaning from the brushwork and ink technique. Inscription also plays a supporting role in the virtual environment of landscape painting. Su Shi once said: "poetry cannot be done, so it becomes calligraphy and the calligraphy becomes 
painting", which clarifies the relationship of poetry, calligraphy and painting. Before the Yuan Dynasty, the literati put inscriptions out of scroll or at the corner of the scroll. The purpose was to not affect the overall beauty of the picture. But since the Yuan Dynasty, the literati were no longer restrained by it and began to inscribe words in the painting, and the number of word is not limited, so they created the poetry painting mode. In fact, it does not affect the overall beauty of the painting. On the contrary, it underlines the virtual environment of the landscape painting. But at the same time, it needs to point out that both poetry inscription and seal inscription have certain regularity to not destroy the overall view of the picture as premise.

\section{CONCLUSION}

In Chinese traditional culture the doctrine of $\mathrm{Lao} \mathrm{Zi}$ and Zhuang Zi has always occupied an important position, which unavoidably influenced many fields in ancient cultural creation. Take traditional Chinese landscape painting as an example. The empty and clam core ideas of Lao $\mathrm{Zi}$ and Zhuang $\mathrm{Zi}$ have important humanistic significance after being extended and developed from virtual environment to realistic environment. In the creation of landscape painting, the construction of virtual environment is of its core significance. In nowadays, the science and technology develop rapidly and many cultures develop together, foreign ideas are easily confused with Chinese traditional culture, which makes people lose themselves. It has a certain negative effect on the spirit of Chinese traditional landscape painting. The author believes that we should follow the cultural connotation and spirit of the traditional landscape painting, continue to inherit and innovate on the basis of it, develop the cultural roots of the landscape painting, so that make the cultural value of the virtual environment construction in landscape painting develop further in the contemporary time.

\section{REFERENCES}

[1] Yu Jianhua. Classified Compilation of Ancient Chinese Painting, People's Fine Arts Publishing House (reprinted in technique), Beijing. 俞剑华. 中国古代画论类编[M], 人民美术出版社, （在技法上重 印), 北京。

[2] Niu Kecheng. Chinese Painting of Colors. Hunan Art Publishing House, Changsha. 牛克诚.色彩的中国绘画[M].湖南美术出版社, 长沙。

[3] Wang Huangsheng and Hu Guanghua. A Special History of Chinese Painting: Landscape. Nanchang: Jiangxi Art Publishing House, 2008. 王 璜生、胡光华著.中国画艺术专史山水卷 [M]. 南昌: 江西美术出版 社,2008.

[4] Zong Baihua. Aesthetics and Artistic Conception. Nanjing: Jiangsu Literature and Art Publishing House, 2008. 宗白华.美学与意境[M].南 京: 江苏文艺出版社, 2008 .

[5] Peng Jixiang. Chinese Arts. Beijing: Peking University Press, 2007. 彭 吉象.中国艺术学[M].北京: 北京大学出版社, 2007.

[6] Tian Chuanliu. Aesthetics of Art. Shandong: Shandong People's Publishing House, 2007. 田川流著. 艺术美学[M].山东: 山东人民出 版社, 2007. 